\title{
CONTRATRANSFERÊNCIA DO PSICÓLOGO COORDENADOR DE GRUPOS
}

\author{
Juliano Corrêa* \\ Nedio Seminoti**
}

\section{RESUMO}

O objetivo do artigo é estudar a contratransferência do psicólogo coordenador de grupo, como ele trabalha com a mesma, que eventuais dificuldades encontra para tal. $\mathrm{O}$ método de análise do material foi o qualitativo, coletado através de uma entrevista semiestruturada respondida por quatro psicólogas que trabalham com grupos abertos apoiadas no referencial psicanalítico. As entrevistas foram gravadas e transcritas e, posteriormente, submetidas à análise de conteúdo. Pôde-se identificar sentimentos do psicólogo despertados na situação de grupo e como ele maneja os mesmos. Também foram discutidas as particularidades da contratransferência na situação de grupo, aspectos referentes à formação do psicólogo e à questão dos grupos na psicanálise.

Palavras-chave: contratransferência, grupos, psicanálise

\section{Abstract \\ COUNTERTRANSFERENCE OF THE GROUP COORDINATOR PSYCHOLOGIST \\ The objective of this research is to study the countertransference of the psychologist as a coordinator of group, how he deals with it, which difficulties he may face. To reach this objective a qualitative method was used. Four female psychologists who worked with groups based on the psychoanalytic theory answered a semi-structured interview which was recorded, transcribed and analyzed through the method of content analysis. It was possible to identify the different}

* Psicólogo; Psicanalista; Mestre em Psicologia Clínica - PUCRS.

** Psicólogo; Doutor em Psicologia pela Universidad Autónoma de Madrid; Professor do Programa de Pós-Graduação em Psicologia da PUCRS e Coordenador do Grupo de Pesquisa "Relações Grupais: Emergentes e Organizaçōes". 
feelings of the psychologist that emerge in the group situation and to see how he manages them. Characteristics of countertransference in a group situation, questions concerning groups in psychoanalysis and the professional formation of the psychologist are discussed.

Keywords: countertransference, groups, psychoanalysis

Conforme a literatura (Béjarano, 1978; Moscovici, 1985; Etchegoyen, 1989; Kaës, 1993; Zimerman, 1999; Shepard, 2000), o grupo e a contratransferência não têm recebido a devida importância na psicanálise e, em conseqüência, há pouco conhecimento sobre o tema. Por essa razão, torna-se pertinente compreender como o psicólogo trabalha com a contratransferência na situação de grupo e discutir a relação do impacto da contratransferência com a disponibilidade de trabalhar com grupos, assim como as possíveis dificuldades com os sentimentos contratransferenciais nesse contexto.

Existem diferentes entendimentos sobre contratransferência: alguns autores a entendem como algo exclusivamente inconsciente; outros, como também consciente. Segundo D. E. Zimerman (comunicação pessoal, 17 de março, 2003), a contratransferência pode ser vista como algo inconsciente e também consciente. Desta forma, vamos considerar, neste artigo, contratransferência e sentimentos como equivalentes.

A contratransferência foi, durante a primeira metade do século XX, pouco explorada e entendida somente como entrave ao processo psicanalítico (Etchegoyen, 1989; Laplanche e Pontalis, 1997; Zimerman, 1999). Ainda hoje, é um tema que traz incômodo para os psicanalistas. "Diferentemente do que aconteceu com o fenômeno transferencial, cujo reconhecimento trouxe muito alívio aos analistas, a contratransferência continua provocando problemas de desconforto nos terapeutas" (Zimerman, 1999: 348). O artigo de Heimann (1949/1990) é considerado o marco a partir do qual a contratransferência passou a ser vista também como instrumento imprescindível para o analista. Desde então, vários autores estudaram o tema (Dewald, 1989; Bollas, 1992; Zimerman, 1999), que ainda é impreciso e de difícil abordagem.

Também o grupo, como afirmamos, foi colocado em segundo plano na psicanálise. Os textos sociais de Freud que serviriam para o estudo dos grupos foram, e são até hoje, atacados por várias razões (Moscovici, 1985). No entanto, nas obras de Freud existem importantes contribuições: a descrição do início da civilização, calcada na culpa pelo assassinato do pai primevo e todo-poderoso, postulando o Complexo de Édipo não apenas como fundador, mas mantenedor da sociedade (Freud, 1913/1974); a identificação com o líder, representante do 
ideal de ego dos membros do grupo (Freud, 1921/1974); o narcisismo das pequenas diferenças (Freud, 1930/1974), que indica que, para existir harmonia num grupo, deve haver outro grupo às expensas do qual se possa dar vazão aos impulsos hostis. Ele sublinha as modificações que ocorrem no indivíduo quando no grupo:

Um grupo é impulsivo, mutável e irritável. É levado quase que exclusivamente por seu inconsciente... Não pode tolerar qualquer demora entre seu desejo e a realização do que deseja. Tem um sentimento de onipotência: para o indivíduo num grupo a noção de impossibilidade desaparece (Freud, 1921: 101).

Bion (1970) concorda: no grupo as emoções se elevam e a capacidade intelectual diminui. Idéia desenvolvida por Anzieu (1993), que postula uma tripla regressão no grupo: cronológica (ameaça da perda da identidade do ego pelo confronto com os outros); tópica (grupo se torna substituto do primeiro objeto parcial de amor, o seio, perdido); e formal (volta a expressôes arcaicas próximas ao processo primário). Daí a dificuldade entre os membros do grupo de manter contato através do processo secundário.

O Id está presente num grupo da seguinte forma: a pluralidade dos indivíduos evoca, para cada membro, a diversidade das pulsões libidinais e agressivas: a pulsão de um só. De um ponto de vista psicanalítico estrutural, não há outro problema num grupo senão os da satisfação da pulsão e da natureza dos mecanismos preparados para atingi-la (Anzieu, 1993: 60).

O ego arcaico corporal que se desenvolve do id para se defender das pulsões é representado pelo líder ou coordenador. A partir do ego evoluído de cada um, o grupo forja um ego comum autônomo capaz da auto-regulação e controle da pulsão. Nesse ego fictício se desenvolve um superego e um ideal de ego do grupo. O estudo dos grupos teria grande avanço se essas instâncias fossem estudadas em sua gênese e funções, se os fenômenos fossem relacionados aos movimentos destas e se os grupos fossem estudados de acordo com sua estruturação metapsicológica (Anzieu, 1993). Com a mesma preocupação, Kaës (1993) salienta que seria de grande valor uma elaboração metapsicológica dos grupos a fim de incrementar seu estudo na psicanálise.

Quanto à teoria da técnica psicanalítica dos grupos, a contratransferência é muito mais que um simples eco inconsciente mobilizado pelas transferências. Manifesta-se não só em relação aos participantes, mas ao grupo como objeto libidinal e a colegas de equipe (Anzieu, 1978). O autor aponta que, se, no trabalho individual, a análise da contratransferência é necessária de vez em quando, no 
grupo é quase permanente. Percebe-se uma mudança na passagem da relação com um paciente para a relação com vários. $\mathrm{O}$ grupo exige mais do terapeuta acerca da sua capacidade contratransferencial, devido ao maior número de identificaçôes e transferências cruzadas (Zimerman, 1999). Anzieu (1993) sublinha que o avanço das práticas de terapia em grupo é tido como uma ameaça ao indivíduo e à sociedade, visto que remete aos núcleos neuróticos e provoca mecanismos de defesa do ego entre os próprios psicanalistas. Sobre tais resistências a pensar em grupo, lembra que, se Freud já falava da resistência à psicanálise, maior seria a resistência à dinâmica dos grupos.

Considerando o exposto, formulamos o seguinte problema a ser pesquisado: como o psicólogo trabalha com a contratransferência no grupo? Para responder a essa pergunta desenvolvemos os seguintes objetivos: (1) discutir se o número reduzido de pessoas trabalhando com grupos num referencial psicanalítico se deve ao impacto da contratransferência; (2) levantar dados sobre que dificuldades existiriam para o psicólogo aceitar e usar seus sentimentos contratransferenciais no contexto do grupo.

\section{MÉTOdo}

Uma metodologia para se analisar dados qualitativos é a análise de conteúdo (AC). Constantino (2002) afirma que a análise de conteúdo serve como técnica de leitura e interpretação de qualquer material escrito e que "produzir inferência ou desvelar significados é a razão de ser da AC” (Constantino, 2002: 187). Quanto ao tratamento da técnica, afirma que enquanto uns postulam que deve ser feita uma análise estatística dos dados, outros apontam para uma leitura densa do material estudado. Portanto, a técnica a ser utilizada está vinculada ao interesse de quem faz a pesquisa e às particularidades da mesma, avaliadas pelo próprio pesquisador.

\section{Participantes}

O critério para a escolha dos participantes foi que trabalhassem como coordenadores de grupo abertos em hospitais públicos, nos quais os pacientes que fazem parte do grupo não têm uma regularidade obrigatória de presença. Esses grupos têm freqüência semanal e são classificados, segundo os critérios propostos por Zimerman (1993), como grupos terapêuticos de auto-ajuda. Os coordenadores participantes da pesquisa têm experiência de no mínimo dois anos neste trabalho e se guiam pelo referencial psicanalítico. Observando os critérios menciona- 
dos, foram escolhidas, por conveniência, quatro psicólogas que trabalhavam em diferentes hospitais.

\section{Procedimentos para Coleta e Análise dos Dados}

A seguir, todo o material escrito foi submetido à avaliação de dois juizes psicólogos reconhecidos para a função, a fim de manter a fidedignidade dos dados. As participantes assinaram um termo de consentimento que explicita os procedimentos aqui delineados. Elas escolheram seus próprios nomes fictícios, que aparecem na apresentação dos resultados.

As entrevistas tiveram uma duração média de 40 minutos. Foram pautadas por questóes como: "que tipos de sentimentos são despertados quando trabalhas com grupos?"; "de que forma tu ages em relação a tais sentimentos?"; "existem dificuldades em lidar com esses sentimentos?"; "como tu vês a demanda dos psicólogos para o trabalho com grupos atualmente?”. As questóes da entrevista foram criadas após a realização de uma entrevista piloto.

\section{ApresentaÇão dos RESUltados}

$\mathrm{Na}$ análise de conteúdo das entrevistas, foram observadas 3 categorias a priori, que se referiam aos objetivos do projeto, e 2 a posteriori, que emergiram do processo de análise do material coletado. Entre todas estas categorias, elegemos para a discussão neste momento 3 categorias que se mostraram mais significativas para nossos objetivos no processo de discussão dos resultados. A análise das categorias será apresentada a seguir com trechos das entrevistas que ilustram as mesmas.

\section{Categoria Manejo dos Sentimentos Despertados}

Nesta categoria estão agrupadas as unidades de análise que se referem às atitudes tomadas pelas participantes da pesquisa, apoiadas nos seus sentimentos despertados no trabalho com grupos.

\section{1. Pelo terapeuta}

Aqui estão agrupadas as unidades que se referem às intervenções feitas, ou não, pelo psicólogo, guiado pelos seus sentimentos no trabalho com grupos. São abordados aqui tanto os manejos considerados positivos como os negativos pelas participantes. Destacam-se questões como:

(a) Devolução feita para o grupo pelo psicólogo em relação aos sentimentos despertados em seu trabalho, sendo que 3 das participantes relataram fazerem tal devolução sempre para o grupo, não de uma forma individual, como no exemplo 
que segue: "geral... cada pessoa que fala é um porta-voz do grupo. Claro, se ela expressou, é um pouco dela, um pouco do grupo, mas a gente não vê isso individualmente" (Joana).

(b) Elaboração posterior da contratransferência em um momento pós-grupo, através de uma avaliação, pelo psicólogo, dos seus sentimentos: “Às vezes tu não se dá conta na frente das pessoas, aí dá um tempo, se afasta e noutra situação que não tem nada a ver, aparentemente, tu se dá conta: ah, mas era aquilo...” (Fernanda).

(c) Atitude defensiva tomada pelo psicólogo em relação aos sentimentos que lhe foram despertados: "me sinto muito cansada, e já sei quando me sinto cansada porque a tendência, na hora de interpretar, é ir para algo muito intelectualizado, uma defesa na intelectualização" (Laura).

(d) Resposta agressiva do psicólogo ao(s) participante(s) do grupo devido aos sentimentos que lhe foram despertados: "fizeram colocações de forma mais agressiva e realmente dessa vez isso me pegou. Me incomodei muito, porque o jeito que a pessoa colocou foi muito agressivo, desrespeitoso. E respondi de uma forma bem agressiva também (risos)" (Débora).

\section{2. ATRIBUÍdOS AO GRUPO}

Aqui estão agrupadas unidades de análise que se referem ao manejo atribuído pelo psicólogo aos membros do grupo em relação aos sentimentos que lhe foram despertados. São abordados, segundo a opinião dos participantes da pesquisa, manejos considerados positivos e negativos.

(a) Identificação, referente ao apoio que, segundo o ponto de vista do psicólogo, acontece entre os integrantes do grupo: "colaboro para que o grupo tenha um funcionamento mais saudável. Esse seria meu maior papel. Mas acho que a ajuda maior realmente vem das pessoas" (Débora).

(b) Negação de certa situação ou sentimento atribuída pelo psicólogo aos participantes do grupo: "então, naquele dia, me lembro que as pacientes não queriam fazer grupo. Não posso compactuar com a negação delas” (Joana).

\section{CATEGORIA IMPACTO DA CONTRATRANSFERENCIA}

Nesta categoria estão agrupadas as unidades de análise que se referem a como os sentimentos que são despertados no psicólogo no trabalho de grupo são recebidos pelo mesmo, como ele sente o que lhe é despertado e possíveis dificuldades de manejo. Destacam-se as questões:

(a) Intensidade, grau de força com que o psicólogo experimenta os sentimentos que lhe são despertados no trabalho com grupos: "qualquer coisa que 
sinto, sinto muito forte... como se potencializasse. E não em progressão aritmética, mas em progressão geométrica. Acho que é um aumento grande” (Laura).

(b) Sentimento sem Palavras. Refere-se a um sentimento associado a uma dificuldade de expressão, despertado no psicólogo no trabalho com grupos: "porque são sentimentos ainda sem palavras, exatamente por isso que são passados para mim, porque senão não precisariam ser passados por essa via, que acho que é uma via que foge do discurso" (Laura).

(c) Exposição. Refere-se a uma suposta maior exposição do psicólogo no trabalho com grupos: "acho que pega um lado mais fóbico. Antigamente, acho que me assustava mais com grupos: é muita gente, falam todos ao mesmo tempo, o que priorizo? Então, acho que a gente fica um pouco mais ansiosa. Acho que exige mais experiência e jogo de cintura. Acho que tem que ter coragem, do quanto a gente tem coragem de se expor e enfrentar aquela situação, não ficar com medo" (Fernanda).

\section{Categoria FormaÇÃo do PSicólogo}

Nesta categoria estão agrupadas as unidades de análise que se referem à formação do psicólogo e à influência da mesma em relação à contratransferência, com destaque para o tratamento pessoal do psicólogo e sua relação com os aspectos contratransferenciais.

"Porque é uma coisa tão intensa, praticamente uma avalanche, como uma avalanche de neve mesmo. E isso, vejo, por exemplo, nos estagiários. Por que alguns estagiários conseguem e outros não, coordenar o grupo? Acho que tem a ver com isso: uma capacidade psíquica pra suportar essa avalanche que vem" (Laura).

\section{Discussão}

$\mathrm{Na}$ primeira categoria apresentada, aparecem verbalizações que apontam para uma devolução do que o psicólogo sente ao grupo como uma totalidade. Ainda que este dado aponte para uma valorização do uso da contratransferência, traz particularidades interessantes a serem discutidas. Três das 4 entrevistadas relataram dar suas devoluçôes sempre para o grupo, nunca para seus membros individualmente. É claro que existem razões teóricas para isso. Caparrós, inclusive, afirma: "não deliram, certamente, aqueles terapeutas que fazem suas interpretações para o grupo" (Caparrós, 1993: 84). Nas verbalizações deste mesmo item, há uma curiosidade quanto à afirmação da participante Laura, quando esta relata que usa "nós" em suas interpretações, já que se inclui no grupo. Isso vai ao encontro do 
que Schulte (2000) e Bollas (1992) escrevem sobre a subjetividade do coordenador de grupo e como ele se insere nas interpretações. Mesmo assim, podemos ir um pouco além neste ponto.

É muito comum ouvirmos falar do grupo: o grupo está chato, o grupo está trabalhando bem, etc., sem discriminar a instituição grupo de seus constituintes. Isso, como vimos, não está incorreto. O grupo é um objeto de análise e intervenção reconhecido, inclusive para se fazer uma interpretação (Zimerman, 1993). O que procuramos abordar é que dirigir sempre as intervenções ao grupo significa deixar de lado as particularidades das pessoas que formam o grupo. Segundo sugere a análise do material coletado, isso parece ser uma maneira de defesa contra a "galeria de espelhos", produzida pelos membros do grupo, como disse a participante Fernanda. É uma maneira de evitar a "avalanche" da multiplicidade de sentimentos que compóem o grupo, na expressão usada pela participante Laura. Há indicação de que, ao abster-se de lidar com as diferenças entre os indivíduos, o psicólogo se protege atrás da igualdade entre eles. Podemos afirmar que há razões particulares de cada psicólogo para tomar essa ou aquela posição e isso não pode ser simplesmente diluído em um oceano grupal. $\mathrm{O}$ próprio Freud, ao definir a regressão no grupo, escreve: “um grupo (grifo nosso) é impulsivo, mutável e irritável. É levado quase que exclusivamente por seu inconsciente...” (Freud,1921/1974: 101). Podemos constatar que as diferenças individuais são olvidadas e os que estudamos grupo a partir das idéias de Freud incorremos no mesmo vício. Com isso, o complexo processo de grupo fica simplificado, o que nos ajuda a mitigar os afetos desencadeados. Podemos supor que Freud estaria se referindo às pessoas na situação de grupo. Talvez isso pudesse ser relacionado também com a $2^{\text {a }}$ subcategoria.

Quando o psicólogo atribui ao grupo o manejo dos sentimentos despertados nele mesmo, podemos pensar essas atitudes como um afastamento do psicólogo do que ele sente, de modo a não se chocar com a dificuldade em lidar com seus sentimentos. Além disso, é importante ressaltar que as perguntas às participantes da pesquisa foram sempre em relação a elas, ao que elas sentiam, a como elas lidavam com isso. Assim, julgamos que não se pode deixar de observar o fato de manejos terem sido abordados pelas psicólogas com relação ao grupo, quando na entrevista se perguntava sobre seus sentimentos. $O$ foco da entrevista era nelas. Costumamos trabalhar com o que os outros sentem, mas, muitas vezes, não conseguimos encarar o que nós mesmos sentimos! Kunzler escreve que "desenvolveuse uma atitude quase fóbica em relação aos próprios sentimentos. $\mathrm{O}$ medo da contratransferência poderia levar o analista a sufocar qualquer reação humana natural frente ao paciente" (Kurzler, 1994: 33). 
Devido a toda a rede de identificações que ocorrem no campo grupal, a situação de grupo tende a ser complexa (Zimerman, 1971). Assim, parece que, quando os participantes da pesquisa se referem ao grupo de uma forma geral, deixando de lado as pessoas do grupo, podem estar se esquivando de algo difícil: lidar e fazer uso do que sentem. Béjarano (1978) e Piñero e Casado (2001) sublinham aspectos semelhantes quanto às dificuldades do psicanalista em lidar com a contratransferência, principalmente na questão de grupo; Dewald (1989) mostra a dificuldade do psicólogo em encarar seus próprios conflitos psíquicos.

Ainda na primeira categoria apresentada, há relatos de uma defesa do ego como maneira de lidar com os sentimentos. O que nos interessa aqui é que, se esta situação está ocorrendo, deve ser porque algo não está sendo bem elaborado pelo psicólogo. É difícil trabalhar com o que se sente e, além disso, desempenhar a tarefa de coordenador durante a sessão. Alguns autores, como Bion (citado por Zimerman, 1995), pensam que isso nem mesmo seja possível. Porém o próprio Zimerman (1995) afirma a possibilidade de insights contratransferenciais durante a sessão terapêutica. Nas falas das participantes da pesquisa, fica clara essa dificuldade e a necessidade de uma elaboração posterior. Neste ponto, contribuem as idéias de Bollas (1992), ao afirmar que, mesmo sem saber de seus sentimentos, o analista deve se colocar como objeto de análise do paciente e dele próprio. Da mesma forma que se costuma dizer que a análise é uma construção, a compreensão da contratransferência também o é. Como os achados da pesquisa indicam, o coordenador precisa tomar distância da experiência do grupo para compreender seus sentimentos e articulá-los com o processo do grupo.

Sobre a categoria seguinte, como o psicólogo vivencia sentimentos contratransferenciais, talvez o discutido aqui tenha relação significativa com a intensidade do sentimento. Quando autores destacam a complexidade que o grupo envolve (Anzieu, 1993; Zimerman, 1993; Freud, 1921/1974), nos remetemos à intensidade dos sentimentos produzidos, sublinhada pelas participantes da pesquisa. Assim, podemos pensar que esta intensidade se multiplicaria a partir do momento em que existem vários pacientes na situação terapêutica, tornando-a mais complexa. Aumentada a intensidade dos sentimentos, aumentaria a exigência de trabalho interno do psicólogo e assim ele estaria mais exposto. Restaria a pergunta: que exposição seria essa?

Ogden (1997), segundo nosso ponto de vista acompanhando o pensamento de Bollas (1992) referido acima, usa a contratransferência como meio fundamental para abordar os sentimentos de vitalização e desvitalização da análise, mas não recomenda uma confissão dos sentimentos para o paciente. Do mesmo modo como apareceu nessa categoria, a segunda apresentada, sobre o impacto da 
contratransferência, trata-se de um sentimento sem palavras expressado pelos pacientes que é projetado sobre o psicólogo, justamente para que ele possa vertê-lo em palavras. Zimerman (1995) sublinha a extrema necessidade de o psicólogo funcionar como continente destes sentimentos sem palavras, objetivando a comunicação no grupo. A pesquisa indica que pode haver temor do psicólogo de exporse em demasia quando coloca palavras nos sentimentos inefáveis dos pacientes, pois isso o faz tomar contato direto com seus sentimentos. A participante Laura dá um exemplo disso quando afirma que é necessária uma capacidade psíquica para suportar este sentimento sem palavras que é passado para o psicólogo. Embora Bion (1970) afirme que muitas das interpretaçôes do psicólogo encontram base nos seus sentimentos, sendo a comunicação no grupo muitas vezes feita somente pelas emoções, não podemos desconsiderar que isso expõe o psicólogo, às vezes, de maneira insuportável.

Verbalizações como a da participante Débora, sobre como trabalha com os sentimentos frente ao grupo, reforçam este aspecto: "olha, não sei, tô achando meio chato hoje. O que será que está acontecendo?". Porém complementa: "no grupo eu não tenho feito isso com freqüência, mas acho isso importante". Sua fala sugere que nem sempre o psicólogo pode trabalhar com seus sentimentos.

Assim, chegamos à importante questão sobre a formação do psicólogo. Apesar do reconhecido valor de outros fatores como supervisão e estudo teórico, o tratamento pessoal é o que merece maior atenção na abordagem da relação contratransferencial. Uma das razões é o fato de que, ao não dar devida atenção à contratransferência, quanto mais teoricamente instrumentalizados ficamos, mais facilmente poderemos nos esconder atrás de uma teoria muito bem sabida por nós, como assentaram Anzieu, Béjarano, Kaës, Missernard e Pontalis (1978). Aqui vemos uma estreita referência à questão já abordada da elaboração posterior, pois, conforme as verbalizações das participantes da pesquisa, o tratamento pessoal seria o caminho mais óbvio para atingir esse objetivo. Freud (1921/ 1974) nos mostrou como a identificação no grupo pode ser complicada quando atravessada por questões pessoais do psicólogo que não estão bem resolvidas. Sobre isso, todas as participantes da pesquisa concordaram: tem de haver um preparo pessoal para o trabalho. A opinião de Bollas sobre esta questão ancora nossa discussão:

nossa maior virtude profissional como psicanalistas é o comprometimento com nossa própria análise pessoal. Por mais impressionante que seja nossa teoria, por mais importante que seja o processo de supervisão, e tão necessária quanto 
é a nossa pesquisa, nada se aproxima à integridade de nossa experiência como $o$ paciente (Bollas, 1992: 310).

Continuando com a discussão sobre a contratransferência no grupo, ressalte-se que vários autores (Anzieu et al., 1978; Enriquez, 1990; Kaës, 1993) fazem referência à questão de como o psicólogo pode sentir-se pouco à vontade na situação de grupo. Este se constituiria como um lugar privilegiado do desejo, como aponta Anzieu (1993). Segundo a tese deste autor, o grupo seria, psiquicamente, um sonho do ponto de vista dinâmico. Sabemos que o sonho é a realização de um desejo infantil que foi recalcado. $\mathrm{Na}$ formação dos sonhos, ocorrem três tipos de regressão, que seriam, na verdade, apenas um e aconteceriam ao mesmo tempo, já que "o que é o mais antigo no tempo é mais primitivo na forma e, na tópica psíquica, fica mais perto da extremidade” (Freud, 1900/1975: 578). A regressão individual poderia ser também uma regressão para além da infância do sonhador, a uma infância filogenética, "uma imagem do desenvolvimento da raça humana, do qual o desenvolvimento do indivíduo é, de fato, uma recapitulação abreviada, influenciada pelas circunstâncias fortuitas da vida" (Freud, 1900/1975: 578).

Béjarano (1978) propõe que, assim como o complexo de Édipo seria estruturante do superego, nos grupos esta estruturação se daria através do mito da horda primeva, através da culpa dos irmãos por terem assassinado o pai. Ou seja: a história que nos é contada por Freud (1913/1974) estaria presente em qualquer grupo e seria seu organizador. Seminoti afirma que os irmãos não foram capazes de conter suas produçóes psíquicas internas, o desejo de tomar o lugar do pai e manter relações sexuais com as mulheres. "Em vista disso, essas pessoas vivem uma regressão genética e adotam condutas com características de fases mais antigas de seu desenvolvimento psicossexual que se refletem na organização do grupo" (Seminoti, 2000: 63).

Assim, chegamos à instalação da horda primitiva no grupo (Anzieu, 1993; Béjarano, 1978). Com o assassinato do pai, segundo construção de Seminoti (2000), cada um dos irmãos tentará, à sua maneira, tomar o lugar do pai e dar vazão ao desejo pelas mulheres. Juntamente, surgem defesas contra seus próprios desejos incestuosos e contra os dos irmãos. Essa situação eleva a ansiedade e faz aumentar a intensidade das atuações dos sentimentos. A horda primeva, então, se estabeleceria no grupo: os participantes seriam os irmãos; o psicólogo coordenador, o pai. Isso explicaria “... as dificuldades dos psicanalistas viverem em grupo (grifo do autor): comunicações difíceis, pouca tolerância, lutas surdas pelo poder ou pela influência, hierarquia. A história do movimento psicanalítico, as tensōes e cisões estão lá para provar" (Béjarano, 1978: 138). 


\section{CONSIDERAÇÕES FINAIS}

Os achados da pesquisa indicam que sentimentos contratransferenciais do psicólogo desencadeados no grupo são mais intensos do que os promovidos na psicoterapia individual e, por essa razão, mais difíceis de operacionalizar. As interações entre os participantes do grupo promovem identificações entre eles com a correspondente ressonância e incremento das produçóes psíquicas ali produzidas. Desse clima de grupo faz parte o psicólogo que o coordena e, nessa condição, é produtor e reprodutor da dinâmica grupal. A pesquisa indica que, às vezes, o psicólogo é incapaz de diferenciar o que é produção sua ou de outras pessoas. Noutras, coloca-se fora do grupo e afirma que o grupo o está aborrecendo, sem poder considerar qual é sua contribuição para o enfado.

Segundo consideramos na pesquisa, para ser eficaz em sua tarefa no grupo, o psicólogo precisa entregar-se à experiência e, simultaneamente, observá-la. Isso significa dizer que, no grupo, o coordenador é produtor do processo e coordenador do mesmo e, nesse papel, precisa colocar-se na condição de analista do grupo do qual faz parte, levando em conta as singularidades de cada membro, inclusive as suas, o que já constitui uma tarefa complexa. Acrescente-se a isso o fato de que o grupo, como pontuamos, é um dispositivo multiplicador e amplificador dos processos individuais, especialmente devido às associaçôes de idéias e afetos, inerente à vida coletiva do pequeno grupo.

Frente a isso, constatamos que os coordenadores tendem a simplificar o complexo. Uma forma de fazê-lo é tratar o grupo como unidade; isso está de acordo com as recomendações teórico-técnicas. No entanto, é importante reafirmar que se trata de uma estratégia com vistas a mitigar a intensidade da contratransferência. Eles o fazem para não se expor a ponto de ver prejudicada sua tarefa de coordenação. No entanto, com isso, colocam em lugar secundário as singularidades, as diferenças e estranhezas entre as pessoas, parecendo que só há entre elas semelhanças. Outro exemplo disso é tomar a expressão individual como sendo representação grupal, sem considerar as contribuições particulares do porta-voz. Simplificase para viabilizar a compreensão do processo do grupo, mas, ao olvidar a articulação indivíduo/grupo, reduz-se o múltiplo ao único.

Os psicólogos entrevistados indicam soluções para resolver os problemas aventados. Dar atenção a uma elaboração posterior, fazer supervisão de seu trabalho e a própria análise. Essas soluções são as mesmas recomendadas pela formação psicanalítica, independentemente de se o psicólogo é terapeuta individual ou grupal. 
Embora esses achados da pesquisa não possam ser estendidos a todas as práticas de grupo de orientação analítica, são úteis para os que se envolvem neste trabalho e, supomos, podem auxiliar a discussão sobre coordenação de grupo.

Outras pesquisas e estudos são necessários para que o valor terapêutico dos grupos seja mais bem avaliado e tenha maior reconhecimento e para que as dificuldades apontadas nesta pesquisa, e outras mais, sejam superadas. Neste sentido, pensamos que pesquisas sobre questões mais específicas, tais como a regressão psíquica, parcial e temporária, desencadeada no grupo, as experiências comuns entre estar no grupo e no sonho, e outros mitos inerentes aos grupos, seriam necessárias. Igualmente, o estudo indica que pesquisas relativas à contratransferência do coordenador seriam úteis ao trabalho com grupos. Afinal, "nenhum psicanalista avança além do quanto permitem seus próprios complexos e resistências internas" (Freud, 1910/1976: 130).

\section{REFERÊNCIAS BIBLIOGRÁFICAS}

Anzieu, D., Béjarano, A., Kaës, R., Missernard, A., Pontalis, J.-B. (1978). O trabalho psicanalítico nos grupos. Lisboa: Moraes editores.

Anzieu, D. (1978). A interpretação e a contratransferência do monitor. Em D. Anzieu, A. Béjarano, R. Kaës, A. Missernard, J.-B. Pontalis. O trabalho psicanalítico nos grupos (pp. 181-184). Lisboa: Moraes editores.

Anzieu, D. (1993). O grupo e o inconsciente - o imaginário grupal. São Paulo: Casa do Psicólogo.

Béjarano, A. (1978). Resistência e transferência nos grupos. Em D. Anzieu, A. Béjarano, R. Kaës, A. Missenard, J.-B. Pontalis. O trabalho psicanalítico nos grupos (pp. 75-146). Lisboa: Moraes editores.

Bion, W. R. (1970). Experiências com grupos. Rio de Janeiro: Imago.

Bollas, C. (1992). Contratransferência. Em C. Bollas. A sombra do objeto (pp. 211-354). Rio de Janeiro: Imago.

Constantino, N. S. de. (2002). Pesquisa histórica e análise de conteúdo - pertinência e possibilidades. Estudos Ibero-Americanos, 23 (1), 183-194. Porto Alegre: EDPUCRS.

Caparrós, N. (1993). Contratransferencia y processo grupal. Em A. Á. Espada (Org.). Manual de psicoterapia de grupo analítico vincular, tomo 2. Madrid: Quipú Ediciones.

Dewald, P. (1989). Psicoterapia: uma abordagem dinâmica (5a ed.). Porto Alegre: Artes Médicas.

Enriquez, E. (1990). Freud e o vínculo social. Em E. Enriquez. Da horda ao estadopsicanálise do vinculo social (pp. 27-178). Rio de Janeiro: Jorge Zahar Editor. 
Etchegoyen, H. R. (1989). Fundamentos da técnica psicanalítica (2a ed.). Porto Alegre: Artes Médicas.

Freud, S. (1900). A interpretação de sonhos. Em Freud, S. Obras completas, vol. V. Rio de Janeiro: Imago, 1975.

(1910). Perspectivas futuras da técnica psicanalítica. Em Freud, S. Obras completas, vol. XI. Rio de Janeiro: Imago, 1976.

. (1913). Totem e tabu. Em Freud, S. Obras completas, vol. XIII. Rio de Janeiro: Imago, 1974.

. (1921). Psicologia de grupo e análise do ego. Em Freud, S. Obras completas, vol. XVIII. Rio de Janeiro: Imago, 1974.

. (1930). O mal-estar na civilização. Em Freud, S. Obras completas, vol. XXI.

Rio de Janeiro: Imago, 1974.

Heimann, P. (1949). Countertransference. Em Langs, R. Classics in psychoanalytic technique (pp. 139-142). New Jersey: Jason Aronson Inc, 1990.

Kaës, R. (1993). El grupo y el sujeto del grupo - elementos para una teoría psicoanalítica del grupo. Buenos Aires: Amorrortu Editores.

Kunzler, F. (1994). Contratransferência ou contra-identificação projetiva. Projecto - revista de psicanálise, 4 (5), 31-38. Porto Alegre: Pontifícia Universidade Católica do Rio Grande do Sul.

Laplanche, J., Pontalis J.-B. (1997). Vocabulário da psicanálise (7ª ed.). São Paulo: Martins Fontes.

Moscovici, S. (1985). La era de las multitudes - un tratado histórico de psicología de las massas. México: Fondo de cultura económica.

Ogden, T. H. (1997). Analisando formas de vitalidade e desvitalização da transferênciacontratransferência. Livro Anual de Psicanálise, 11, 175-188. São Paulo: Escuta.

Piñero, J. A., Casado, A. S. (2001). Observaciones sobre la envidia: "la reación terapéutica negativa”. Clínica y análisis grupal, 23 (86), 63-66. Madrid: Imago.

Schulte, P. (2000). Holding in mind: intersubjectivity, subject relations and the group. Group analysis, 33 (4), 531-544.

Seminoti, N. (2000). La organización y dinámica del grupo psicológico: la multiplicidadl diversidad de organizadores del grupo. Tese de Doutorado. Universidad Autónoma de Madrid, Madrid.

Shepard, J. K. (2000). Female trainees' experience of having sexual feelings toward a male patient while being supervised by a male supervisor. Trabalho de Conclusão. Massachusetts school of professional psychology, Massachusetts. 
Zimerman, D. E. (1971). O psicoterapeuta frente ao grupo como totalidade e a contratransferência. Em D. E. Zimerman. Psicoterapia analítica de grupo (pp. 107-125). São Paulo: Mestre Jou.

. (1993). Fundamentos básicos das grupoterapias. Porto Alegre: Artes Médicas.

. (1995). Bion: da teoria à prática - uma leitura didática. Porto Alegre: Artes Médicas.

. (1999). Fundamentos psicanalíticos: teoria, técnica e clínica - uma abordagem didática. Porto Alegre: Artes Médicas.

Recebido em 15 de junho de 2005 Aceito para publicação em 25 de julho de 2005 